\title{
EFFICIENCY OPTIMIZATION OF A SOLAR BOAT IM DRIVE EMPLOYING VARIABLE DC LINK VOLTAGE AND FUZZY CONTROL
}

\author{
Gilberto C. D. Sousa and Domingos S. L. Simonetti \\ Power Electronics And Drives Laboratory - Department Of Electrical Engineering \\ Federal University Of Espírito Santo - C. P. 01-9011- Vitória - ES - BRAZIL \\ E-mail: g.sousa@ele.ufes.br \\ d.simonetti@ele.ufes.br
}

\section{Ever E. C. Norena}

Faculty of Electronic Engeneering - Universidad Nacional Mayor de San Marcos Ciudad Universitaria. Av. Venezuela Cdra. 34 - Lima 1

E-mail: ecifuentes@viabcp.com

\section{Joost Pieter Rey}

Noordelijke Hogeschool Leeuwarden - 8913 HP Leeuwarden - The Netherlands E-mail: j.p.rey@tech.nhl.nl

\begin{abstract}
This paper describes a fuzzy logic based on-line efficiency optimization control of a solar boat drive that uses an indirect vector controlled induction motor for either speed or torque control. Besides acting on the flux level to reach optimum balance between the core and copper losses, this controller also acts upon the DC link voltage, in order to reduce the inverter losses as well. Due to its quadratic characteristics, the load torque is quite small at low to medium speeds, and the potential for energy saving is great. An experimental drive system with the proposed controller implemented on a TMS320C25 DSP based control board was constructed and tested in laboratory to validate the proposed technique.
\end{abstract}

\section{INTRODUCTION}

A solar boat propulsion system was jointly developed by Noordelijke Hogeschool Leeuwarden (NHL-Holland) and The Federal University of Espírito Santo (UFES - Brazil). Although the entire system is briefly described, only the part developed at UFES (IM drive control) is discussed in details here.

Efficiency improvement in variable frequency drives is getting a lot of attention in the recent years [1,2]. In the present work, somewhat specific goals are present: for a solar powered boat designed to carry tourists through a nature preserve, higher efficiency translates into smaller number of solar panels, less cooling requirements for the converter and motor, with attendant reduction in cost and weight.

The efficiency of a drive system is a complex function of the type of the selected machine, converter topology, type of power semiconductor switches and the PWM algorithm used. In addition, the control system has profound effect on the drive efficiency. It is well known that, for induction motors, the maximum efficiency is obtained when the core losses and the copper losses become equal, at any given torque and speed condition. A drive system normally operating at rated flux gives the best transient response. However, at light load condition, this causes excessive core loss [3], thus impairing the efficiency of the drive. Since drives operate at light load most of the time, optimum efficiency can be obtained by programming the flux. A simple pre-computed flux program as a function of torque is widely used for light load efficiency improvement. The scheme can be improved by generating the flux program at discrete speeds to take the frequency variation into consideration. The losses can also be computed in real time and correspondingly the flux can be assigned so that the system operates with minimum losses [1]. These schemes may be inaccurate because parameter variation is not taken into consideration. The on-line efficiency optimization control [4-6], on the basis of search, where the flux is reduced in steps until the measured input power settles down to the lowest value, is very attractive. The control does not depend on parameters and the algorithm is applicable universally for any arbitrary machine. In the present paper, a fuzzy logic based on-line efficiency optimization control is employed in an indirect vector controlled drive system that assures fast convergence with adaptive step size of excitation current. A feedforward compensation algorithm suppressed the low frequency pulsating torque, generated by the efficiency controller.

Besides acting on the flux level to reach optimum balance between the core and copper losses, this controller also acts upon the DC link voltage, in order to reduce the inverter losses as well. As the load (boat) possesses quadratic torquespeed characteristics, the load torque is quite small at low to medium speeds, and the potential for energy saving is great.

\section{THEORETICAL ANALYSIS}

\section{A - Machine loss modeling}

While the machine copper losses are easily modeled, and clearly dependent on the total rms current, core loss modeling is somewhat more complex. In fact, the commonly used equations are empirically derived. The stator core losses $\left(\mathrm{P}_{\mathrm{cs}}\right)$ due to the fundamental frequency (f) component can be represented by:

$$
\mathrm{P}_{\mathrm{cs}}=\mathrm{k}_{\mathrm{e}} \mathrm{f}^{2} \lambda_{\mathrm{m}}^{2}+\mathrm{k}_{\mathrm{h}} \mathrm{f} \lambda_{\mathrm{m}}^{2}
$$


where $\lambda_{\mathrm{m}}$ is the fundamental air-gap flux, $\mathrm{k}_{\mathrm{e}}$ and $\mathrm{k}_{\mathrm{h}}$ are the eddy current and hysteresis loss coefficients, respectively. Equation (1) can be rewritten in terms of fundamental air-gap voltage $\mathrm{V}_{\mathrm{m}}$ :

$$
\mathrm{P}_{\mathrm{cs}}=\mathrm{k}_{\mathrm{c}}\left(\mathrm{k}_{\mathrm{e}}+\mathrm{k}_{\mathrm{h}} / \mathrm{f}\right) \mathrm{V}_{\mathrm{m}}^{2}
$$

Where $\mathrm{k}_{\mathrm{c}}$ is proportionality constant. From (1) it is evident that the dominant fundamental core losses are highly dependant on the flux level.

When operating under reduced DC link voltage $\left(\mathrm{V}_{\mathrm{dc}}\right)$, extra reduction in core losses can be achieved, as will be demonstrated. For a given fundamental flux level, fixed speed and load torque, the required fundamental inverter voltage is constant, irrespective of the value of $\mathrm{V}_{\mathrm{dc}}$. Clearly, when $V_{d c}$ is reduced, the modulation factor has to increase to keep the fundamental voltage constant. As a consequence, dominant harmonics are greatly reduced, due to both the decrease in $\mathrm{V}_{\mathrm{dc}}$ and the increase in the modulation factor.

Assuming that the core losses caused by the harmonic fluxes are governed by the same principles, expressions similar to (1) and (2) can be obtained, with harmonic fluxes and voltages substituted for $\lambda_{\mathrm{m}}$ and $\mathrm{V}_{\mathrm{m}}$, respectively.

Another consequence of the reduced total harmonic voltage is the decrease in total harmonic current. As a consequence, total rms current also decreases, as do the attendant (stator and rotor) copper losses.

\section{B - Converter loss modeling}

For a sinusoidal PWM inverter utilizing IGBTs, the loss analysis shows that the conduction losses for a given IGBT are proportional to the modulation index $m$, the collector emitter voltage $\mathrm{V}_{\mathrm{CE}}$, and to the collector current $\mathrm{I}_{\mathrm{C}}$ [7]. Under reduced $\mathrm{V}_{\mathrm{dc}}$ operation, $m$ is increased to counteract the reduction in $\mathrm{V}_{\mathrm{dc}}$, such that the required fundamental voltage is produced. As mentioned before, the rms value of the motor current is somewhat reduced, what also tends to produce a small reduction in $\mathrm{V}_{\mathrm{CE}}$. A precise quantitative analysis would be tedious and unnecessary, since It would came to the conclusion that any increase or reduction in the IGBTs conduction losses would be minimal.

The switching losses, however, both during turn-on and turn-off, are independent of the modulation index, but are highly dependent on $\mathrm{V}_{\mathrm{dc}}$ and $\mathrm{I}_{\mathrm{C}}$. Therefore, they are greatly reduced by the proposed technique.

In the freewheeling diodes, the conduction losses diminish when $m$ is increased, and the rms current is decreased. Furthermore, the switching losses are also reduced by both $\mathrm{V}_{\mathrm{dc}}$ and rms current reduction. As a consequence, the overall inverter losses are greatly reduced, resulting in extra efficiency gains for the proposed control technique.

\section{OVERALL SYSTEM DESCRIPTION}

The overall drive system is illustrated in Fig. 1. The power source consists of a $48 \mathrm{~V}$ battery pack fed by solar panels through an optimal power point tracking controller (OPPT). Instead of keeping the DC link voltage constant, as in most VSI industrial drives, here a variable-output boost-type DC-
DC converter can be employed to yield just the voltage level required for proper current control, at partial speeds, resulting in additional efficiency improvements, as discussed above. In addition, this allows an off the shelf induction motor (IM) $(220 \mathrm{~V} / 60 \mathrm{~Hz})$ to be employed, in place of a custom, low voltage IM. Energy captured by the solar panels is stored in a battery pack, that when fully charged reaches $52 \mathrm{~V}$. The selection of such a low battery voltage is aimed at maximizing the number of parallel paths in the solar array. This results in increased reliability, and also permits the selection of a proper $\mathrm{V}_{\mathrm{dc}}$ level at low speeds.

Fig. 2 shows the block diagram of an indirect vector controlled induction motor drive incorporating the proposed efficiency optimization controller that was actually implemented at UFES. The feedback speed control loop generates the active or torque current command ( $\mathrm{i}_{\mathrm{qs}}{ }^{*}$ ), as indicated. The vector rotator receives the torque and excitation current commands $\mathrm{i}_{\mathrm{qs}}{ }^{*}$ and $\mathrm{i}_{\mathrm{ds}}{ }^{*}$, respectively, from the two positions of a switch: the transient position (1), where the excitation current is established to the rated value (idsr) and the speed loop feeds the torque current, and the steady state position (2), where the excitation and torque currents are generated by the fuzzy efficiency controller and feed-forward torque compensator. The fuzzy controller becomes effective at steady state condition, i.e., when the speed loop error approaches zero. Note that the DC link power $\mathrm{P}_{\mathrm{d}}$, instead of input power, has been considered for the fuzzy controller since both follow symmetrical profiles.

\section{A - Current Controller Design}

Industrial vector drives usually utilize PI current control in the synchronous reference frame, with feed-forward terms, to decouple the back EMF effects. The PI gains are selected to produce the required bandwidth, with minimum overshoot. Under variable DC link voltage, the converter gain is no longer constant, and consequently, the current controller performance would deteriorate. Proper control under variable DC link voltage can be achieved with the use of a disturbance input-decoupling block, shown in Fig. 3.

As the variable $V_{d c}$ affects the inverter gain, the block $\mathrm{V}_{\mathrm{dco}} / \mathrm{V}_{\mathrm{dc}}$ (rated / actual $\mathrm{V}_{\mathrm{dc}}$ ) adjusts the loop gain in the opposite way, such that an overall constant loop gain results.

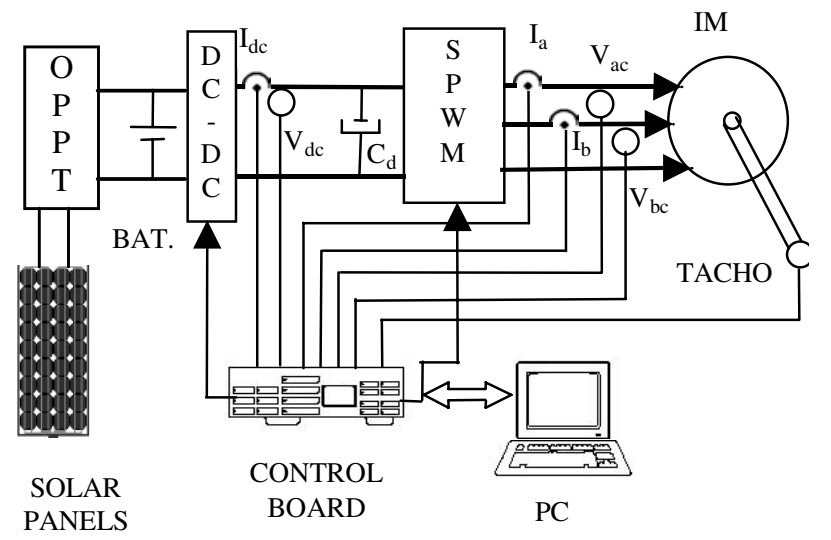

Fig. 1. Overall diagram of the solar boat drive. 


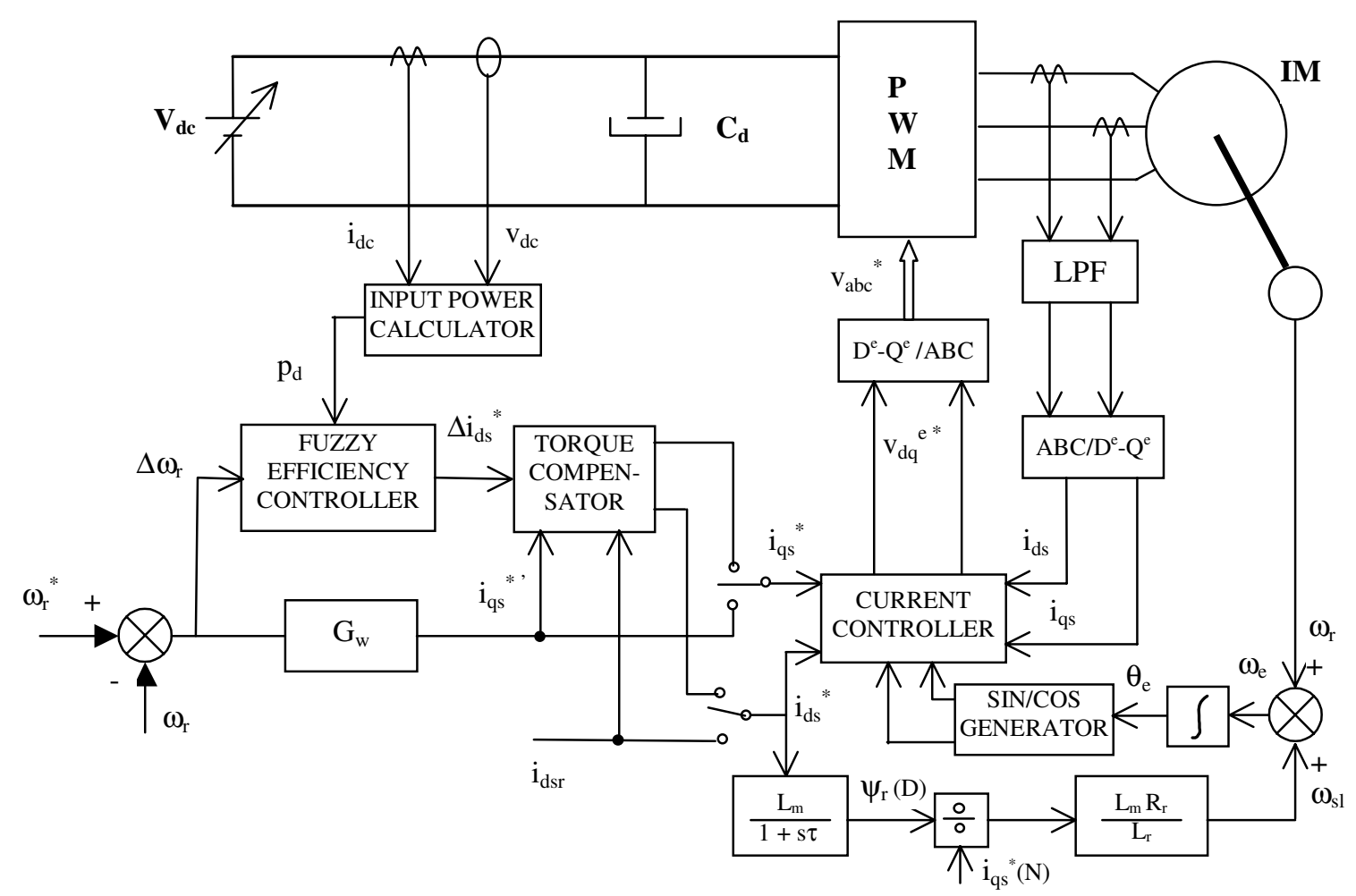

Fig. 2: Indirect vector controlled induction motor drive incorporating the efficiency optimization controller.

\section{B - DC Link Voltage Control}

As stated before, there are several benefits resulting from the operation at reduced $\mathrm{V}_{\mathrm{dc}}$. The system however, must provide enough voltage to ensure proper current regulation at any load and speed condition. To this end, the counter EMF at rated flux was computed as a function of frequency $\left(\omega_{\mathrm{e}}\right)$, and added to the rated stator resistance voltage drop. A boost voltage term was then added to ensure fast current transient (to overcome inductive effects) at any speed. The resulting relationship is shown in Fig. 4, for the case of a $5 \mathrm{hp}, 220 \mathrm{~V}$, $60 \mathrm{~Hz}, 4$ pole induction motor, used in the experimental study. The upper voltage of $300 \mathrm{~V}$ is due to the use, in this phase of the project, of a $220 \mathrm{~V}$ AC mains to supply a fullbridge three-phase diode rectifier, to emulate the solar panels and boost converter, as will be discussed later in the experimental section.
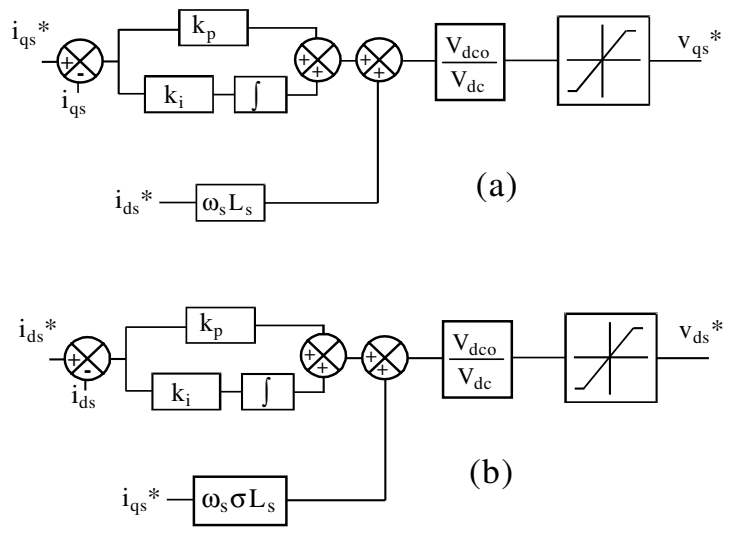

Fig. 3. Current control block diagram.

\section{REAL TIME SOFTWARE DEVELOPMENT}

The experimental system illustrated in Fig. 2 was constructed to supply a $5 \mathrm{hp}$ standard (Class B), 83,5\% rated efficiency IM in the first phase of the project. A $8 \mathrm{~kW}$ high efficiency motor is planned for the actual boat drive.

\section{A - Software Structure}

A control board based on the TMS320C25 DSP from TI INC performs virtually all the control functions. The software structure is depicted in Fig. 5, where it can be seen that there are two distinct interrupts. An INT1 interrupt controls the $\mathrm{A} / \mathrm{D}$ and $\mathrm{D} / \mathrm{A}$ channels, such that a $5 \mathrm{kHz}$ sampling frequency per A/D channel is achieved. Another timer interrupt (TINT), adjusted for $200 \mu$ s, controls the core of the control routines. Due to the slow dynamics of rotor flux, and consequently core losses variations, there is a need to obtain other sampling times, what is easily achieved via software

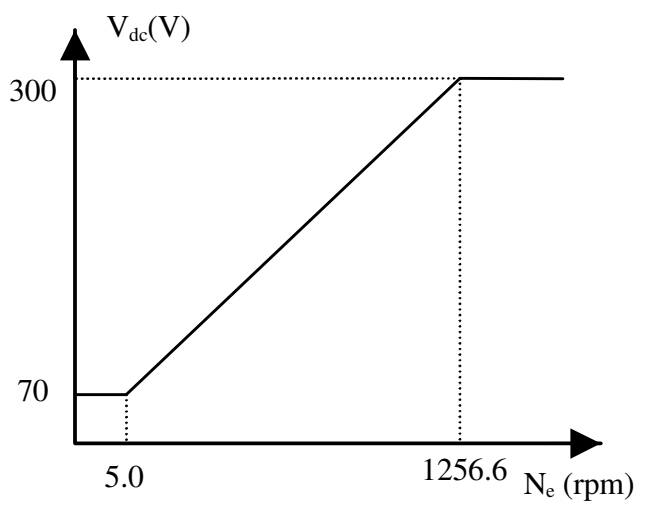

Fig. 4: DC link voltage as a function of machine speed. 


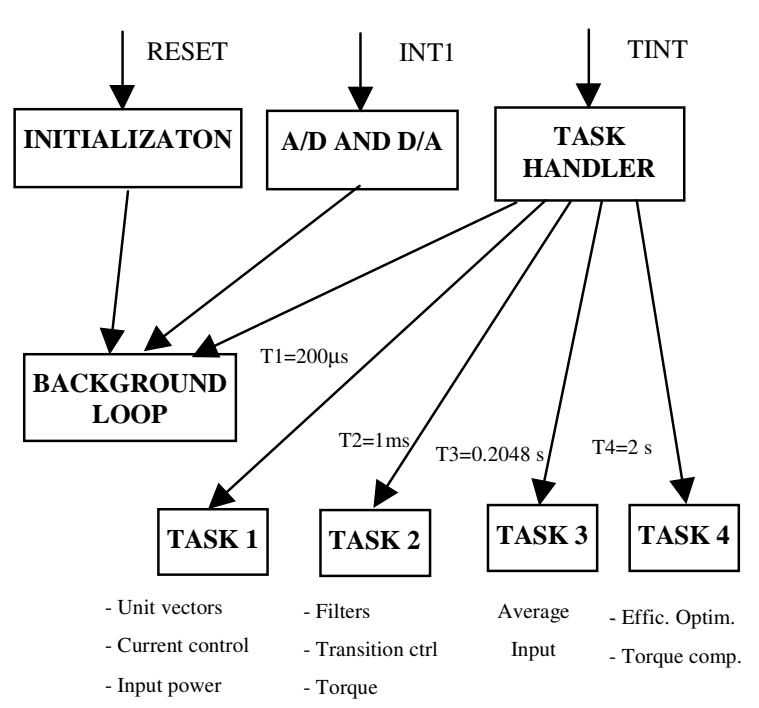

Fig. 5. Real time software flowchart.

timers and a task handler, as indicated.

The unit vectors computation, along with the synchronous frame current control, and instantaneous DC link power computation are performed at the $200 \mu$ s sampling time. A $1 \mathrm{~ms}$ sampling time was utilized for filters that smooth the speed and DC link power signals, in addition to transient to steady state transition control, slip gain computation, and feed-forward torque compensation routines.

The instantaneous DC link power is accumulated for 1024 cycles, and at every $0.2048 \mathrm{~s}$, its average is computed. This mean value is the one used in the flux efficiency controller to prevent erroneous decision due to instantaneous power fluctuation.

Experimental evaluations dictated that a 2 s sampling time be utilized for the actual fuzzy efficiency optimization routine (FEOPT) and feed forward torque compensation routine (FFTC). Smaller sampling times tend to result in oscillatory behavior for the search controller near the optimum efficiency point.

\section{B - Fuzzy Efficiency Optimization}

Fuzzy logic was employed in the construction of the search controller to provide adaptive step size for d-axis current reference $\mathrm{i}_{\mathrm{ds}}{ }^{*}$ (flux command), aiming at reducing the time for the optimum point to be achieved. It will be briefly discussed here, since a detailed description is provided in [6]. Fig. 6 provides details of the efficiency controller. From the measured DC link power variation $(\Delta \mathrm{Pd}(\mathrm{k}))$, and the information on the last step in the flux command $\left(\mathrm{L} \Delta \mathrm{i}_{\mathrm{ds}}{ }^{*}(\mathrm{k})=\Delta \mathrm{i}_{\mathrm{ds}}{ }^{*}(\mathrm{k}-1)\right)$ the controller derives the new step in flux command $\left(\Delta \mathrm{i}_{\mathrm{ds}}{ }^{*}(\mathrm{k})\right)$. Scaling factors $\left(\mathrm{P}_{\mathrm{b}}\right.$ and $\left.\left.\mathrm{I}_{\mathrm{b}}\right)\right)$ are also utilized to make the controller easier to port to different machine ratings.

The rule base was constructed from the intuitive knowledge that helps humans search for the proper tuning of any system: if the optimum point seems to be far away, proceed in large steps. If it appears to be nearing, then reduce the step size. In the case it is detected that it has been passed, then reverse the search direction with reduced step size.

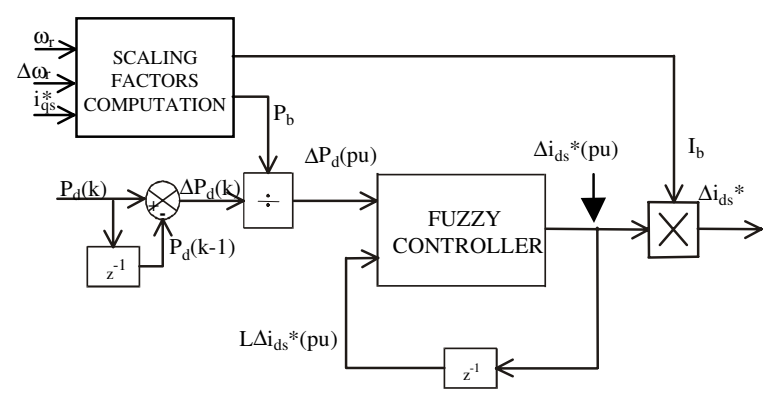

Fig. 6. Fuzzy efficiency search controller.

\section{EXPERIMENTAL RESULTS}

The experimental setup was tested under several load and speed values, both at steady state and dynamic conditions. The system was tested for distinct DC voltage levels, established by a variable AC voltage source and a diode rectifier, to emulate the boost converter. The voltage level was selected based on the characteristics exhibited in Fig. 4.

Initially the impact of the disturbance input decoupling mechanism on the current and speed responses was investigated. Figs. 7 and 8 show the results for both conditions, namely without and with the decoupling mechanism. It can be observed that the current response is faster with the decoupling, what ultimately results in a speed response with smaller overshoot, than that observed for a fixed gain (nominal values).

The efficiency optimization control via flux reduction is illustrated in Fig. 9, for the case of a constant DC link voltage of rated value. The system was initially operating at steady state condition, at $520 \mathrm{rpm}$, already at an optimum flux level. The speed reference was suddenly set to $720 \mathrm{rpm}$, causing the flux producing current component $\left(i_{\mathrm{ds}}{ }^{*}\right)$ to be reset to its rated value $(9.2 \mathrm{~A})$. Fast transient response is then achieved, and after a few seconds, the search algorithm detects a new steady state condition. The flux is next decreased by reduction of excitation current, which correspondingly increases the torque current so that the developed torque remains constant. As the flux is decreased, the iron losses decrease with the attendant increase in copper loss. However, the total system (converter and machine) loss decreases, resulting in a decrease of DC link power. The search is continued until the system settles down at the new minimum input power point.

The effects of each control variable, i.e., rotor flux and DC link voltage, on the drive efficiency can be best visualized in Fig. 10, for the case of a $160 \mathrm{rpm}$ to $360 \mathrm{rpm}$ step in speed reference, and a load torque of 0,04 p.u. at $360 \mathrm{rpm}$. Fig. 10 (a) shows the results for rated $\mathrm{i}_{\mathrm{ds}}{ }^{*}$, rated $\mathrm{V}_{\mathrm{dc}}$, whereas in Fig. 10(b) the optimum flux controller is active, but $V_{d c}$ is kept in its rated value. In contrast, Fig. 10(c) shows how performing $\mathrm{Vdc}$ reduction simultaneously with optimum flux control can substantially reduce the DC link power.

The impact of efficiency optimization is shown in Fig.11, for a 0.4 p.u. speed and several load torques. Case A represents the rated flux, rated DC link voltage operation, whereas case $\mathrm{B}$ is the result of flux optimization alone, as discussed in Fig.10. Curve $\mathrm{C}$ was obtained by simultaneously 

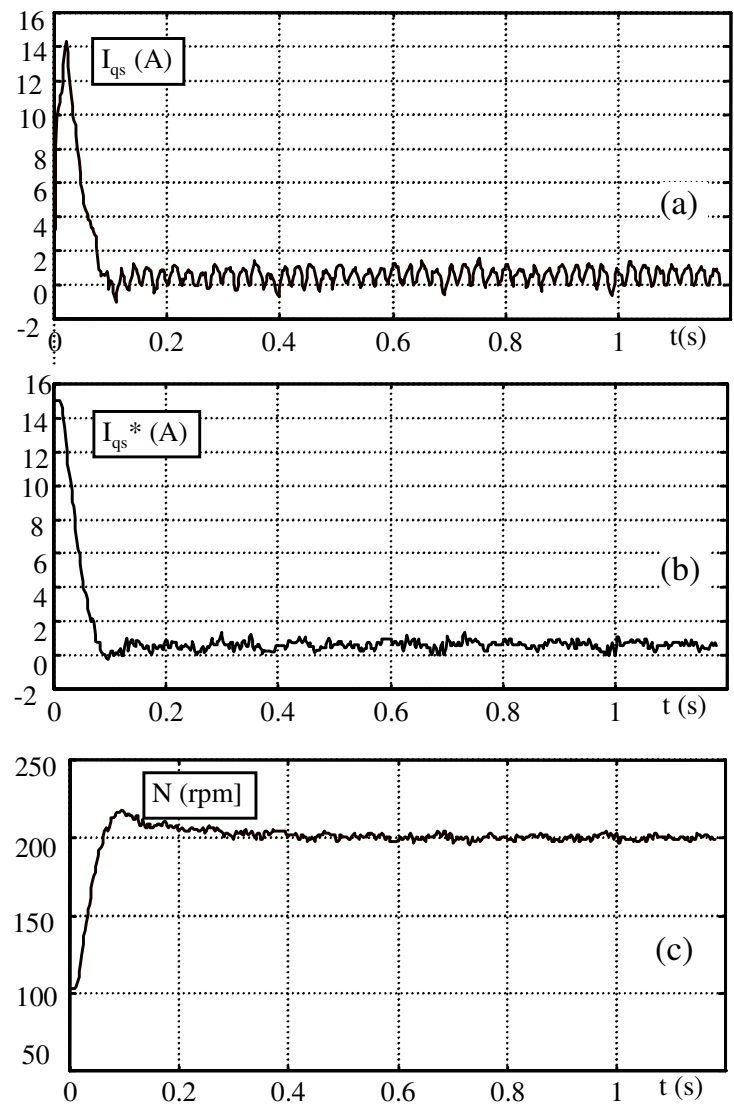

Fig. 7: Response to a speed step from 100 to $200 \mathrm{rpm}$, with $\mathrm{V}_{\mathrm{dc}}=107 \mathrm{~V}$, without the compensation term. (a) Actual $\mathrm{i}_{\mathrm{qs}}$ current; (b) Reference $\mathrm{i}_{\mathrm{qs}}$ * current; (c) Motor speed.

imposing flux optimization along with variable DC link operation. It can be seen that the reduction in the DC link voltage has a significant impact on efficiency for this case. Somewhat similar conclusion can be made for other operating conditions.

\section{CONCLUSIONS}

The paper discussed how the particularities of a solar boat drive can be gainfully utilized to improve the overall drive efficiency. Considering a fixed number of solar panels, the use of a low voltage ( $48 \mathrm{~V}$ ) for the battery pack is a good choice to keep the number of series connected solar cells small, and consequently, increasing the number of parallel paths. This results in increased reliability, and also permits the selection of a proper DC link voltage level at partial speeds.

The problem of proper current control under variable inverter input voltage was addressed, with the help of a decoupling mechanism. This allowed current response to became immune to $\mathrm{V}_{\mathrm{dc}}$ variations. Experimental results were obtained, initially for operating points along the quadratic torque-speed characteristics of the load, for three conditions: rated flux and $\mathrm{V}_{\mathrm{dc}}$, rated $\mathrm{V}_{\mathrm{dc}}$ and optimum flux control, and finally, for simultaneous optimum flux and variable $V_{d c}$ operation.

The benefits of applying optimum flux level, along with
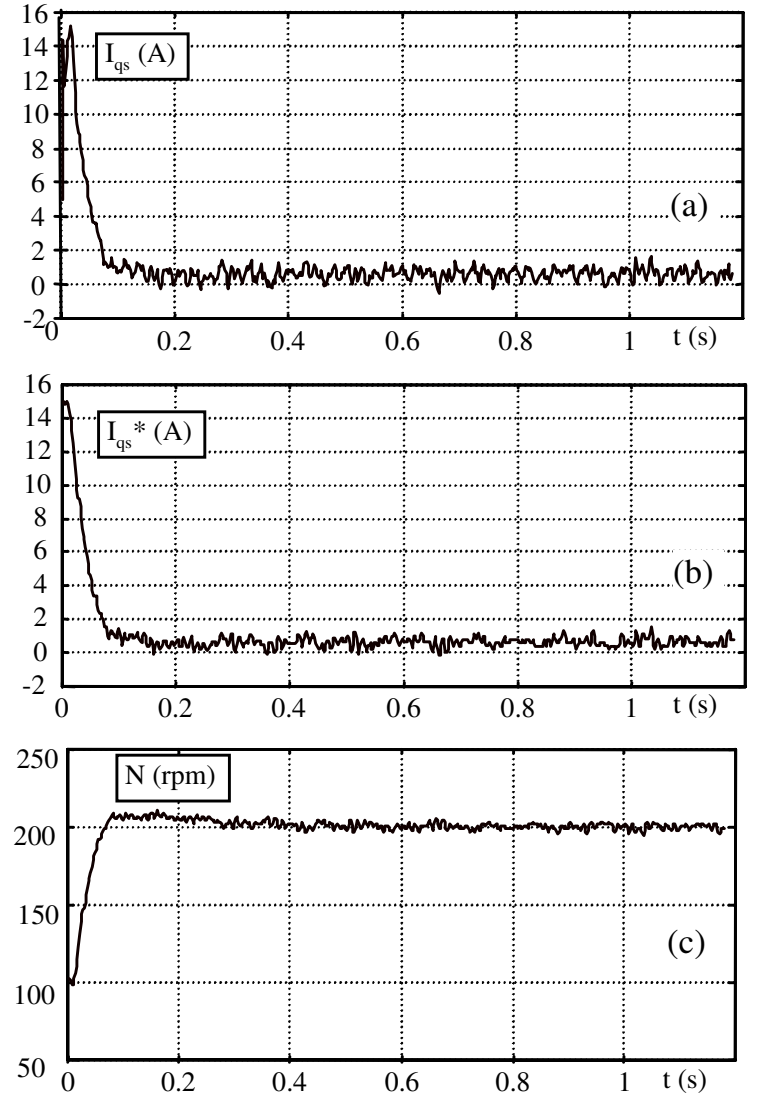

Fig. 8: Response to a speed step from 100 to $200 \mathrm{rpm}$, with $\mathrm{V}_{\mathrm{dc}}=107 \mathrm{~V}$, with the compensation term. (a) Actual $\mathrm{i}_{\mathrm{qs}}$ current;

(b) Reference $\mathrm{i}_{\mathrm{qs}} *$ current; (c) Motor speed.

reduced $\mathrm{V}_{\mathrm{dc}}$ control at low to medium speeds (and torques) were clearly demonstrated, and comprises lower machine losses, lower inverter losses, reduced cooling requirements, and increased reliability due to lower voltage stress on the switch. It can also be demonstrated that this strategy has a beneficial impact on the DC-DC boost-type converter as well. Overall efficiency can be even greater if a low resistance machine is employed, as is the case of a high efficiency induction motors.

\section{ACKNOWLEDGMENTS}

The authors wish to express their gratitude to $\mathrm{CNPq}$, for its financial support of this project.

\section{REFERENCES}

[1] J. Abrahamsen, J. K. Pedersen, F. Blaabjerg, "State-ofthe-Art of Optimal Efficiency Control of Low Cost Induction Motor Drives", Power Electronics and Motion Control PEMC'96, vol. 2, pp. 163-170, Budapest, Hungary, 2-4 September 1996.

[2] F. Abrahamsen, F. Blaabjerg, J. K. Pedersen, P. Z. Grabowski, P. Trogersen, "On the Energy Optimized Control of Standard and High-Efficiency Induction Motors in CT and HVAC Applications ", IEEE Trans. on Ind. App., vol. 34, no. 4, pp. 940-945, July/August 1998. 

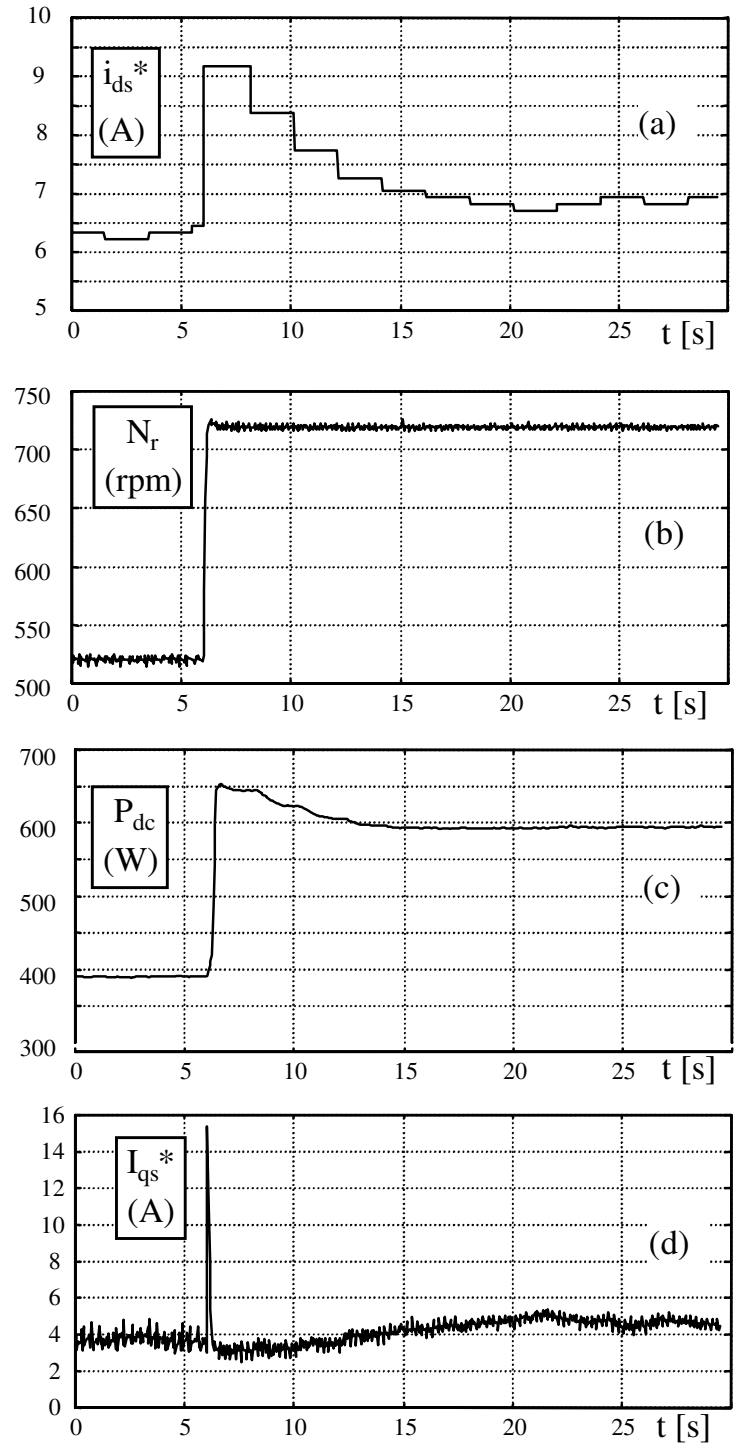

Fig. 9: System behavior for a 520 to $720 \mathrm{rpm}$ step, load torque of $0.16 \mathrm{pu}$, flux optimization at rated Vdc. (a) D-axis current reference; (b) Speed; (c) DC-link power;

(d) Q-axis current reference.

[3] G. C. D Sousa, B. K. Bose, J. G. Cleland, R. J. Spiegel and P. J. Chappell, "Loss modeling of converter induction machine system for variable speed drive", IEEE/IECON Annual Meet. Conf. Rec. Vol. 1, pp. 114-120, 1992.

[4] P. Famouri and J. J. Cathy, "Loss minimization control of an induction motor drive", IEEE Ind. App. Soc. Trans; Jan-Feb, 1991, Vol. 27, no. 1, pp 33-37.

[5] D. S. Kirchen et al., "On-line efficiency optimization of a variable frequency induction motor drive", 1984 IEEE/IAS Annual Meet. Conf. Rec., pp. 488-492, 1984.

[6] G. C. D. Sousa, B. K. Bose and J. G. Cleland, "Fuzzy logic based on-line efficiency optimization control of an indirect vector controlled induction motor drive", IEEE Transactions on Industrial Electronics, Vol. 42 No. 2, pp. 192-198, April, 1995.

[7] F. Casanellas, "Losses in PWM inverters using IGBTs", IEE Proceedings on Electronic Power Applications, September 1994, vol. 141, pp. 235-239.
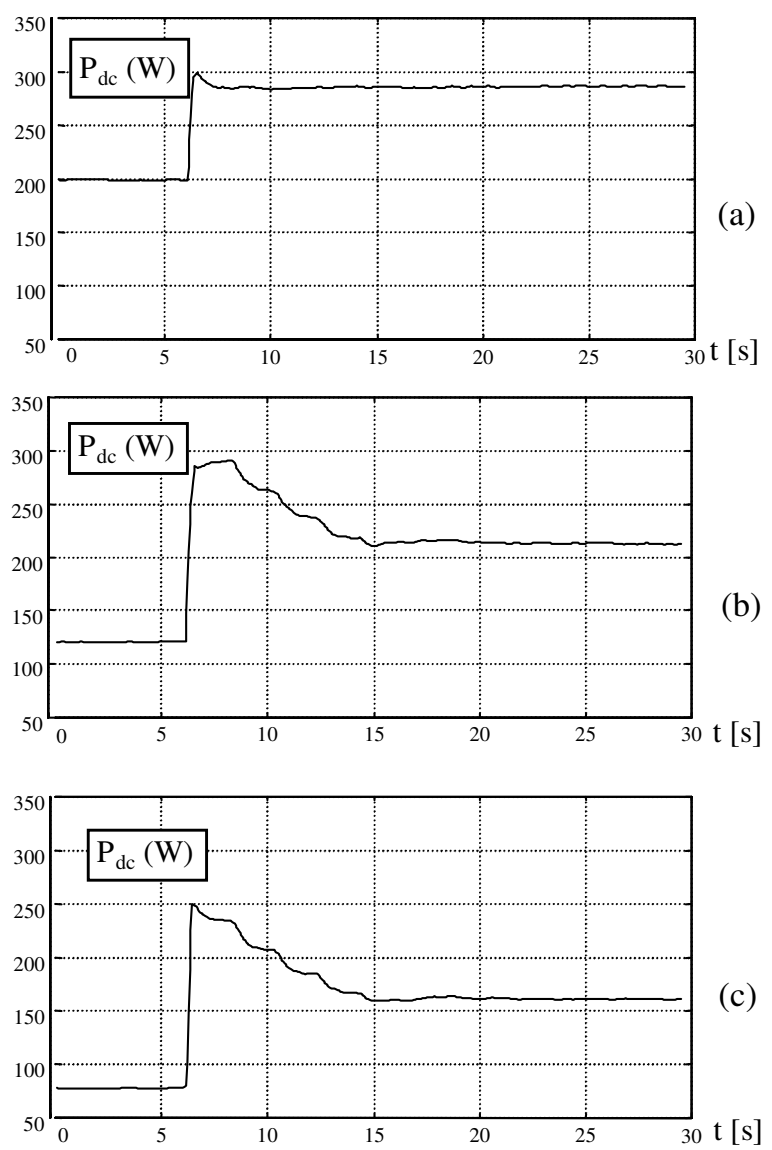

Fig. 10. DC link power for a 160 to $360 \mathrm{rpm}$ speed step, with $\mathrm{TL}=0.04(\mathrm{pu})$. (a) Rated $\mathrm{V}_{\mathrm{dc}}, \mathrm{i}_{\mathrm{ds}}{ }^{*}$, (b) Rated $\mathrm{V}_{\text {dc }}$, optimum $\mathrm{i}_{\mathrm{ds}}{ }^{*}$; (c)

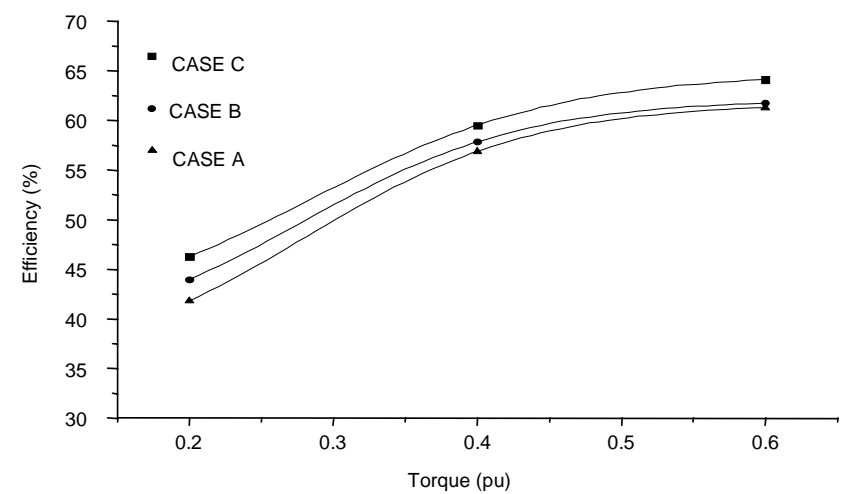

Fig. 11: Efficiencies for a 0.4 pu speed and several load torques.

\section{BIOGRAPHIES}

Gilberto Costa Drumond Sousa received his B.Sc. degree from the Federal University of Espirito Santo (UFES), Brazil, a M.Sc. degree from the Federal University of Santa Catarina, Brazil, and a Ph.D. degree from the University of Tennessee, USA, all in Electrical Engineering. He has been with UFES' Electrical Engineering Department since 1982, where he has been teaching power systems, electrical machines and drives courses for both graduate and undergraduate students. His research interest includes high 
performance drives, power factor correction, and emerging technologies. He is a member of IEEE Industry Application Society, Brazilian Society of Automatic Control, and Brazilian Power Electronics Society.

Domingos Sávio Lyrio Simonetti received his B.Sc. degree from the Federal University of Espírito Santo (UFES), Brazil, a M.Sc. degree from the Federal University of Santa Catarina, Brazil, and a Ph.D. degree from the Universidad Politécnica de Madrid, SPAIN, all in Electrical Engineering. He has been with UFES' Electrical Engineering Department since 1984. His research interest includes soft-switching techniques, power quality, hugh-power factor converters and high performance drives. He is a member of Brazilian Power Electronics Society, IEEE Industrial Electronics Society and Brazilian Society of Automatic Control.

Ever Ernesto Cifuentes Noreña received his B.Sc. degree from the Universidad Nacional Mayor de San Marcos - Lima -Perú (1988), and a M.Sc. degree from the Federal University of Espírito Santo (UFES), Brazil, in 1999. From 1989 until the present time he works as a professor in the Universidad Nacional Mayor de San Marcos (Faculty of Electronic Engineering), in the area of Automatic Control. Also works in the Instituto Peruano de Energía Nuclear in the area of Engineering, since 1988. His research interest includes application of artificial intelligence in control, drives of electrical machines and industrial automation.

Joost Pieter Rey received his B.Sc. and D.Ing degrees from the Technical University of Delft - The Netherlands. From 1972 to 1974 he has worked at the Federal University of Paraíba, and from 1974 to 1984 at the Federal University of Espírito Santo, both in Brazil. He has been with the University of Professional Education Leeuwarden - The Netherlands since 1984. His research interest includes high electrical machine analysis, electrical drives and power electronics, power system control and intelligent control methods. He is a member of Dutch Royal Institute for Engineers (The Netherlands) and of IEEE (USA). 